JAVIER CANOSA

Pontificia Universidad de la Santa Cruz, Roma

\title{
EL BUEN USO DE FORMULARIOS EN LAS CURIAS DIOCESANAS COMO EXPRESIÓN DE LA FORMALIDAD ADECUADA DE LA ADMINISTRACIÓN ECLESIÁSTICA
}

Sumario: - 1. La formalidad de los procedimientos en la Iglesia. - 2. Algunos interrogantes ante los numerosos tipos de formalidades. - 3. ¿Cuál es la medida para valorar si la formalidad de un procedimiento es adecuada jurídicamente? -4 . ¿Por qué resulta importante que quienes usan las formalidades entiendan la razón de su utilización? - 5. ¿Cómo transmitir que la colaboración en un procedimiento administrativo de la Iglesia supone también un servicio pastoral? - 6. Las posibilidades diferentes que ofrecen las colecciones de formularios.

\section{La formalidad de los procedimientos en la Iglesia}

Una de las líneas de cambio que se advierten en las modificaciones introducidas por el Papa Francisco en el proceso matrimonial canónico incide en las formalidades procesales para que, sin dejar de aportar la garantía que ofrecen, se descarguen de tramites excesivos gracias a "una adecuada simplificación".

\footnotetext{
1 "He decidido establecer con este Motu proprio disposiciones con las cuales se favorezca no la nulidad de los matrimonios, sino la celeridad de los procesos y, no en menor medida, una adecuada simplificación, de modo que, a causa de un retraso en la definición del juicio, el corazón de los fieles que esperan la clarificación del propio estado no quede largamente oprimido por las tinieblas de la duda." (Francisco, Carta Apostólica en forma de "Motu Proprio» Mitis Iudex Dominus Iesus sobre la reforma del proceso canónico para las causas de declaración de nulidad del matrimonio
} 
Cabe plantearse una opción similar en referencia a otros procedimientos jurídicos que intervienen en la vida del Pueblo de Dios y que, por ello mismo, también "deben tender al fin de comunicar la gracia divina y favorecer continuamente, según los dones y la misión de cada uno, el bien de los fieles, en cuanto fin esencial de la Iglesia"2.

En efecto, todas las formalidades procedimentales de la administración eclesiástica encuentran su justificación en el servicio real que prestan, razón por la que, observando el Derecho canónico, necesitan ser adecuadas ${ }^{3}$. Consecuentemente deben responder a las exigencias que nacen de la relación de justicia establecida entre los titulares de la potestad ejecutiva de gobierno y los destinatarios de la actividad que estas autoridades ejercen ${ }^{4}$. Lo contrario sucedería por ejemplo si, a causa de automatismos en la aplicación de una norma o por el mero uso repetido desde tiempo remoto, se exigieran trámites demasiado complejos, cuyo aporte fuera de difícil comprensión por parte del interesado directo o que, simple y llanamente, no promoviesen bien eclesial alguno. Un problema parecido se produciría si quienes ejercen la función pastoral, al utilizar determinadas formalidades legales para la realización de un bien, no entendiesen del todo el porqué de esas actuaciones, generándose al fin una dificultad para

en el Código de Derecho canónico, 15 de agosto de 2015, en «L’Osservatore Romano», 9 septiembre 2015, pp. 3-4 y también en www.vatican.va).

${ }^{2}$ Cf. Pablo VI, Discurso a los participantes en el II Congreso Internacional de Derecho Canónico, 17 septiembre 1973, en «L'Osservatore Romano, ed. semanal en lengua española», 23 septiembre 1973, p. 8, citado en Francisco, Carta Apostólica en forma de "Motu Proprio» Mitis Iudex Dominus Iesus, cit.

${ }^{3}$ En palabras de un autor francés, pionero del Derecho administrativo canónico, "les formalités de procédures jouent le rôle de cadres et de routes plaçant et maintenant l'Administrateur dans la constante perspective de la constitution et des buts propres de l'Eglise et par le fait même en présence et en préoccupation du seul service de l'intérêt général chrétien." (J. F. Noubel, Procédures administratives éparses dans le Code de Droit Canonique non rassemblées dans la III Partie du Livre IV, Revue de Droit Canonique 7[1957], pp. 137-161, p. 145).

${ }^{4}$ Cf. sobre este punto C. J. ERrÁzuriz M., Corso fondamentale sul diritto nella Chiesa. I. Introduzione. I soggetti ecclesiali di diritto, Milán 2009, pp. 338-349. 
llevar a cabo ese tipo de cometidos con la plena conciencia del servicio que suponen ${ }^{5}$.

Si la autoridad competente percibiera alguno de estas disfunciones (u otras semejantes), se vería llamada a introducir una mejora en el sentido de la simplificación, o bien de la clarificación, de la actualización, o quizá de la instrucción de las personas, con el objetivo de dotar a las formalidades que sean necesarias de la calidad suficiente para que resulten adecuadas y, en definitiva, justas, por su capacidad de responder satisfactoriamente al derecho de los fieles a la buena administración, al buen gobierno ${ }^{6}$.

\section{Algunos interrogantes ante los numerosos tipos de formalidades}

Al tratar este tema de las formalidades procedimentales en la Iglesia debe tenerse en cuenta que no se está haciendo referencia a una realidad marginal o de entidad menor. De los procedimientos administrativos, con las respectivas formalidades anejas, se vale el Papa, por ejemplo, para convocar una asamblea del Sínodo de los Obispos, o para actuar una reforma de la Curia romana; contando con procedimientos administrativos es como puede programarse y llevarse a cabo un viaje apostólico o, en un nivel diferente, como un Obispo en la diócesis de la que es pastor puede erigir una nueva parroquia, nombrar el rector del seminario de la propia circunscripción eclesiástica, establecer un fondo diocesano para ayuda de las personas necesitadas; y también, gracias a estos instrumentos jurídicos procedimentales, resulta factible que un superior religioso admita un nuevo miembro en su Instituto, que un Vicario episcopal con competencia en materia de enseñanza conceda la autorización

\footnotetext{
${ }^{5}$ Dando lugar, quizá a posibles reservas de tenor parecido a "lo que hago es mera burocracia, ahoga la pastoral", "no tiene mucho sentido tanta rutina", "para qué sirve todo este papeleo", etc.

${ }^{6}$ Vid. acerca de este derecho de los fieles, J. Miras, Derecho al buen gobierno en la Iglesia: una glosa a la doctrina constitucional de Javier Hervada desde el Derecho administrativo, Ius Canonicum, Volumen especial, 1999, pp. 367-377.
} 
a un profesor para que imparta lecciones de religión en una escuela, o que un párroco proceda legítimamente a la celebración de una boda en el templo parroquial. Todos estos actos, que atañen, de un modo u otro, a la administración eclesiástica, han sido preparados por un procedimiento administrativo, a través del cual se ha llevado a cabo el estudio de las noticias recibidas inicialmente y se han realizado otras actividades previas, aptas para recabar algunos datos relevantes, efectuar verificaciones, solicitar la participación de diferentes personas con capacidades distintas, de manera que el resultado pretendido por la autoridad responda a las aspiraciones de la Iglesia.

En los ejemplos apenas mencionados de diferentes intervenciones pastorales que precisan la realización de un previo procedimiento administrativo canónico, se refleja que las manifestaciones numerosas y variadas - de estas formalidades se presentan en niveles y con alcances distintos. Y ciertamente la constatación de la cantidad elevada de tipologías procedimentales existentes en la vida de la Iglesia conduce a plantearse, también a la luz de la reciente reforma procesal impulsada por el Papa Francisco, algunos interrogantes, entre otros, los siguientes:

¿Cuál es la medida para valorar si la formalidad de un procedimiento es adecuada jurídicamente? ¿Por qué resulta importante que quienes usan esas formalidades entiendan la razón de su utilización?¿Cómo transmitir que la colaboración en un procedimiento administrativo de la Iglesia supone también un servicio pastoral?

Aunque lógicamente excede de estas líneas pasar revista a todas las formas administrativas de la Iglesia, al menos se procurará ofrecer un esbozo de respuesta - necesariamente sucinta - a las cuestiones planteadas, por si puede propiciar la introducción de oportunas mejoras procedimentales.

\section{3. ¿Cuál es la medida para valorar si la formalidad de un procedimiento es adecuada jurídicamente?}

En determinadas ocasiones el legislador fija de manera explícita los parámetros de la formalidad adecuada como ocurre, por ejemplo, cuando el Código de Derecho Canónico prescribe que los actos 
de curia requieren para su validez la firma de la autoridad que los produce ${ }^{7}$.

Distinto es el supuesto en el que la ley indica sólo implícitamente a qué requisitos deben ajustarse las formalidades procedimentales para resultar adecuadas. Es así como sucede en el caso del can. 57 al establecerse por el CIC que la autoridad debe adoptar el acto administrativo en el plazo de tres meses desde la solicitud legítima del mismo ${ }^{8}$. En este segundo supuesto únicamente si la tramitación se realiza con la celeridad necesaria que permita observar ese plazo general, podrá ser calificada de "adecuada".

\footnotetext{
${ }^{7}$ CIC, can. 474: "Los actos de la curia llamados a producir efecto jurídico deben ser suscritos por el Ordinario del que provienen, como requisito para su validez, así como también por el canciller de la curia o un notario; el canciller tiene obligación de informar al Moderador de la curia acerca de esos actos." Para conocer una recopilación de normas procedimentales extracodiciales, cf. M. DEL Pozzo, J. Llobell, J. MiÑambres (eds.), Norme procedurali canoniche commentate, Roma 2013.

${ }^{8} \mathrm{CIC}$, can. 57: $\$ 1$. "Cuando la ley prescribe que se emita un decreto, o cuando el interesado presenta legítimamente una petición o recurso para obtener un decreto, la autoridad competente debe proveer dentro de los tres meses que siguen a la recepción de la petición o del recurso, a no ser que la ley prescriba otro plazo”.\$2. "Transcurrido este plazo, si el decreto aún no ha sido emitido, se presume la respuesta negativa a efectos de la proposición de un posterior recurso". $\$ 3$. "La presunción de respuesta negativa no exime a la autoridad competente de la obligación de emitir el decreto, e incluso de reparar el daño que quizá haya causado conforme al can. 128."
}

${ }^{9}$ El Directorio para el ministerio pastoral de los Obispos (CONGREgACIÓn PARA Los OвIspos, Directorio para el Ministerio Pastoral de los Obispos Apostolorum Successores, 22 de febrero de 2004, Ciudad del Vaticano 2004, también en www. vatican.va) recoge está previsión en la letra i de su n. 69: "La rápida solución de los asuntos es norma de ordinaria administración y también de justicia hacia los fieles (nota 178: Cf. Código de Derecho Canónico, can. $221 \$ 1$ ). Cuando la ley prescribe que el Obispo tome medidas en una determinada cuestión o si el interesado presenta legítimamente una instancia o un recurso, el decreto debe ser emitido dentro de tres meses (nota 179: Cf. Código de Derecho Canónico, can. 57)." Sobre este documento, vid. A. W. Bunge, El Directorio para el Ministerio Pastoral de los Obispos Apostolorum Successores, Anuario Argentino de Derecho Canónico 12(2005), pp. 117-164 y A. Viana, El gobierno de la diócesis según Derecho en el directorio "Apostolorum Successores», Ius Canonicum 46 (2006), pp. 639-659. 
Dentro del marco legal se dan, sin embargo, muchos casos en los que, a falta de determinaciones específicas, el procedimiento se configura sobre todo según principios generales - legalidad, carácter público, participación, objetividad, verdad material, celeridad, motivación de las decisiones, derecho a la revisión de los actos, entre otros -, es decir "normas fundamentales, bien precisas, relativas a la formación de los actos administrativos canónicos, las cuales responden a algunos principios de buen gobierno que después, en virtud de su recepción en las leyes, se convierten en principios de justicia legal"10. La aplicación de los principios generales del procedimiento adquiere, por tanto, mayor trascendecia en ámbitos en los que la norma legal no ha delineado la formalidad adecuada, circunstancia que exige a la autoridad a quien se confía el procedimiento actuar con una sensibilidad jurídica mayor, consciente de que la mera formalidad procedimental de por sí es insuficiente para contribuir al bien común si no es utilizada de un modo justo o, mejor, si no se considera como una verdadera ayuda al pastor para que ejerza su oficio a la manera de un servicio desempeñado en orden al fin salvífico de la Iglesia ${ }^{11}$.

\section{4. ¿Por qué resulta importante que quienes usan las formalidades entiendan la razón de su utilización?}

El postulado inicial para la reflexión sobre este punto es que la aptitud de los procedimientos administrativos eclesiales se mide en función del bien que procuran a la Iglesia en cuanto permiten, a quienes ejercen la función pastoral de gobierno - y a los demás que colaboran en esa tarea -, contribuir eficazmente al bien de cada

\footnotetext{
10 "Esistono alcune norme fondamentali ben precise riguardanti la formazione degli atti amministrativo canonici, le quali rispondono ad alcuni principi di buon governo che poi, in virtù della loro ricezione nelle leggi, diventano anche principi di giustizia legale." (C. J. Errázuriz M., Corso fondamentale sul diritto nella Chiesa, cit., p. 341).

${ }^{11}$ Acerca de la importancia de esta concepción, que está fuertemente radicada en la doctrina cristiana, cf. J. Miras, Sentido ministerial de la potestad de gobierno y tutela jurídica en el Derecho administrativo canónico, Fidelium Iura 7 (1997), pp. 29-70.
} 
persona que recibe ese servicio de la autoridad, salvaguardando las exigencias de justicia ${ }^{12}$.

Aunque sin referirse directamente a las formalidades procedimentales adecuadas, Javier Hervada observa a este respecto que "el principio de la forma abarca todo el orden jurídico, también los actos de la autoridad. Éstos se expresan en formas y fórmulas, valen en cuanto están formalizados y formulados y se interpretan en función de aquéllas. Quizás en ningún otro campo puede ofrecer este principio mayores garantías de defensa a los derechos de la persona. En Derecho canónico este principio está bien recogido por lo que se refiere a la actividad de los tribunales. No así en la actividad legislativa ni en la administrativa, con la consiguiente secuela de inseguridad en la interpretación y del riesgo de arbitrariedad en los órganos administrativos"13.

Bien se puede afirmar, por ello, que la formalidad del procedimiento, si es adecuada, favorece la seguridad jurídica ${ }^{14}$, reforzándo la justicia y el buen gobierno - también en la medida en que evita la improvisación -, y resultando así conveniente para los destinatarios de la actividad de la administración eclesiástica, que no son sólo los fieles, puesto que con frecuencia se benefician también personas no pertenecientes a la Iglesia.

Obviamente, la formalidad comporta un grado sujección de quienes intervienen en los procedimientos - sean o no autoridades a las disposiciones del Derecho, con la consiguiente limitación. Cabe recordar en este punto que "no toda limitación es mala, ya que el poder discrecional está sometido a límites, tanto por su fin (debe estar orientado al bien público), como por los medios (que han de

\footnotetext{
${ }^{12}$ C. J. ERrázuriz M., La persona nell'ordinamento canonico: il rapporto tra persona e diritto nella Chiesa, Ius Ecclesiae 10(1998), pp. 3-36, en las pp. 10-11 observa hasta qué punto puede resultar costoso que, en el sistema canónico, sea acogida con todas sus consecuencias la centralidad de la persona, aunque la solución a esa cuestión parezca clara en los fundamentos del sistema.

${ }^{13}$ J. Hervada, Introducción al estudio del derecho canónico, Pamplona 2007, p. 115.

${ }^{14}$ Cf. J. A. Araña, Seguridad jurídica, en J. Otaduy, A. Viana, J. Sedano (eds.), Diccionario General de Derecho Canónico, Cizur Menor 2012, vol. VII, pp. 224-227.
} 
ser honestos), los motivos (deben ajustarse a la verdad) y la forma de expresión (que importa sea clara e inteligible)"15. Esa limitación sana requiere ser comprendida y acogida con conciencia eclesial de servicio. Y no solamente en situaciones en las que el déficit jurídico del derecho sustancial necesita compensarse, al menos en parte, por las garantías formales del procedimiento.

La actividad administrativa de los pastores, "no es, de por sí, un medio para satisfacer un interés cualquiera, sino un instrumento cualificado para cumplir el deber de justicia de dar a cada uno lo suyo", como afirmó Benedicto XVI refiriéndose al proceso matrimonial, con palabras que también se ajustan plenamente a toda formalidad procedimental adecuada ${ }^{16}$.

Desde ese punto de vista, la baja estima por la forma que se advierte, por ejemplo, cuando se minimiza la realización de un procedimiento administrativo acudiendo a un argumento del estilo "es sólo una formalidad" y tratando tal actividad como algo prescindible o casi superfluo, reclama un cambio de perspectiva dirigido a reforzar en la autoridad competente la responsabilidad, la pericia o la diligencia capaces de percibir las ventajas que produce aplicar cumplidamente la formalidad al supuesto concreto y de excluir el desinterés hacia esas previsiones de carácter administrativo ${ }^{17}$.

Simultáneamente se debe evitar el formalismo equivocado u obsoleto. A este propósito, se ha señalado que "incluso pueden darse circunstancias tan materiales como la existencia en almacén de

\footnotetext{
${ }^{15}$ E. Labandeira, Cuestiones de Derecho Administrativo Canónico, Pamplona 1992 , p. 34.

${ }^{16}$ Benedicto XVI, Discurso al Tribunal de la Rota Romana con ocasión de la inauguración del Año judicial, 28 de enero de 2006, en AAS 98 (2006) p. 136.

${ }^{17}$ No resulta superfluo observar que "una mal entendida opción de lo pastoral sobre lo administrativo ha llevado a que en algunos casos los párrocos hayan descuidado este aspecto o encomendado a otros dicha tarea sin la debida supervisión. Por eso no estaría de más que este tema se tratara específicamente en la formación de los seminarios y que esta capacitación básica pudiera luego ser profundizada en el marco de la formación permanente." (J. SAN José PRISCO, Derecho parroquial. Guía canónica y pastoral, Salamanca 2008, p. 435).
} 
impresos antiguos - por ejemplo, formularios de uso menos frecuente, pero de los que en su día se hizo una gran tirada - que, llegado el caso, se utilizan, aunque quizá ya no son adecuados". Tras referirse a este ejemplo, el mismo autor concluía reafirmando el valor de lo formal: "es cierto que aquí se trata sólo de una praxis puramente formal, pero lo formal no es poco importante, porque debe contener y proteger adecuadamente lo sustancial"18.

En efecto, si la autoridad se conduce responsablemente entiende que, para que la formalidad sea adecuada, debe actuarse con las modalidades oportunas. Así, por ejemplo, en el expediente para la preparación del matrimonio,

"la postura del interpelado se insta con paciencia y cuidado para captar con precisión y objetividad las verdaderas intenciones sobre el matrimonio (...) y se muestra claramente que el principio guía [en el expediente matrimonial] es la preocupación genuina por el bien de la persona. La cordialidad que se requiere, que va más allá de la buena educación y la cortesía, indica que a quien formula las preguntas - que representa a la autoridad de la Iglesia -, lo que interesa realmente, lo que desea, es que la persona que solicita matrimonio canónico pueda entrar en esta institución de la mejor manera posible. En otras palabras, la cordialidad es algo más que una bondadosidad superficial que sólo busca un consentimiento fácil, y puede ilustrarse mejor con el concepto de la diligencia, que expresa la conciencia del deber y el amor por lo que se está llamado a realizar y por las personas en favor de las cuales cumple su servicio" 19 .

${ }^{18} \mathrm{~J}$. Miras, Renovación de la praxis administrativa en las curias diocesanas, en AA. VV., Actas de las XXII Jornadas de Actualidad Canónica de la Asociación Española de Canonistas (Madrid, 3-5 de abril de 2002), Salamanca 2003, pp. 89-117.

19 "La presa di posizione dell'interpellato viene sollecitata con pazienza e con attenzione per coglierne con precisione e obiettività i veri intendimenti in ordine al matrimonio (...) nonché nel quale si manifesta che si è guidati da una reale preoccupazione per il bene dell'altro. La cordialità che viene richiesta, infatti, al di 
En buena medida, el valor de de los diferentes trámites se realza o se reduce según se manifieste la actitud de la autoridad interviniente. Cuando el pastor comprende el porqué de la formalidad, ésta deja de ser un espectador ajeno, que asiste a un encuentro vital desde una posición anónima y fría, un mal menor al que hay que resignarse, y se convierte en una guía segura para alcanzar un bien objetivo y duradero. Es entonces cuando la forma refleja la objetividad de los fines que persigue quien representa a la Iglesia ${ }^{20} \mathrm{y}$ cuando garantiza que las actividades administrativas no se realizan siguiendo unas intuiciones subjetivas sino que están sujetas a unas disposiciones que posibilitan su orientación hacia esas finalidades eclesiales en todas las etapas de su desarrollo, sin perjuicio del margen de discrecionalidad otorgado a la autoridad responsable del procedimiento. En efecto, también esa discrecionalidad, connatural a la elasticidad propia del Derecho de la Iglesia, contribuye a que la formalidad sea adecuada.

là dell'educazione e cortesia nel tratto, sta a indicare che all'interrogante, il quale rappresenta l'autorità ecclesiale, importa, sta a cuore, interessa realmente che la persona che chiede il matrimonio canonico possa entrare in questo istituto nel modo migliore possibile. La cordialità, in altre parole, è tutt'altra cosa rispetto a una superficiale bonomia che si pone alla ricerca di un facile consenso, e potrebbe al contrario essere meglio illustrata con il concetto di diligenza, che esprime la consapevolezza del proprio dovere e l'amore per quanto si è chiamati a compiere e per le persone a favore delle quali si adempie il proprio servizio." (P. BIANCHI, «Non esiste [...] un matrimonio della vita e un altro del diritto»: l'esigenza di una seria pastorale prematrimoniale e di una coerente prassi giudiziaria, en fase de publicación).

${ }^{20}$ Entre los principios que guían la realización del procedimiento, además del principio de formalidad adecuada, cabe incluir el principio de objetividad, que "por una parte, impone que la formación de la voluntad de la Administración se lleve a cabo a través de cauces formalizados que aseguren la racionalidad y razonabilidad de las decisiones y la eficacia de la actuación administrativa, pero, por otra parte, implica que, al mismo tiempo, en esos procedimientos se tienen que tomar en consideración todos los intereses involucrados, es decir, también los de los particulares afectados por la decisión que se va a adoptar y, en su caso, intereses supraindividuales de tipo colectivo y difuso" (L. M. МACHO, El principio de objetividad en el procedimiento administrativo en «DA. Revista Documentación Administrativa» n. 289, enero-abril 2011, pp. 99-127, p. 103). 


\section{5. ¿Cómo transmitir que la colaboración en un procedimiento administrativo de la Iglesia supone también un servicio pastoral?}

Elencaré a continuación algunas ideas expresadas por el actual Romano Pontífice que, a mi modo de ver, sirven para enmarcar la respuesta a la cuestión planteada. Más que criterios de actividad administrativa se trata de principios básicos de conducta cristiana que, lógicamente, encuentran también aplicación a nuestro tema y que, si resultan encarnados por quienes realizan las formalidades procedimentales, contribuyen activamente a dar el contenido de servicio pastoral que se ejercita con la buena administración. De entre tantas posibilidades, he elegido las siguientes, que el Papa Francisco ha propuesto en la Exhortación apostólica Evangelii gaudium:

1. Hace falta cultivar un espacio interior que otorgue sentido cristiano al compromiso y a la actividad ${ }^{21}$;

2. se requiere saber mirar la grandeza sagrada del prójimo y descubrir a Dios en cada ser humano ${ }^{22}$;

3. es necesario reconocer que el único camino consiste en aprender a encontrarse con los demás con la actitud adecuada, que es valorarlos y aceptarlos como compañeros de camino, sin resistencias internas ${ }^{23}$;

4. debemos ejercitarnos en el arte de escuchar, que es más que oír. Lo primero, en la comunicación con el otro, es la capacidad del corazón que hace posible la proximidad, sin la cual no existe un verdadero encuentro espiritual. La escucha nos ayuda a encontrar el gesto y la palabra oportuna que nos desinstala de la tranquila condición de espectadores ${ }^{24}$;

\footnotetext{
${ }^{21}$ Francisco, Exhortación apostólica Evangelii gaudium, n. 262, AAS 105 (2013), pp. 1019-1137.

${ }^{22}$ Ibid., n. 92.

${ }^{23}$ Ibid., n. 91.

${ }^{24}$ Ibid., n. 171.
} 
5. siempre se debe resistir a la presión del relativismo práctico que supone actuar como si Dios no existiera ${ }^{25}$;

6. no se puede pactar con un "gris pragmatismo de la vida cotidiana de la Iglesia en el cual aparentemente todo procede con normalidad, pero en realidad la fe se va desgastando y degenerando en mezquindad" 26 .

Sin duda cabe afirmar que, para quienes llevan adelante procedimientos administrativos de la Iglesia, empeñarse personalmente en los criterios de conducta cristiana apenas citados y mostrarlos a otros con la propia vida dispone las bases necesarias para transmitir que la tarea que realizan supone también un servicio pastoral. Encuentro obvio, a la vez, que dejar de empeñarse por encarnar alguna de estas máximas dificultaría cualquier intento de superar el mero formalismo en ese tipo de trabajos.

No obstante el dato de experiencia indica que no se llega fácilmente a captar el valor eclesial de las formalidades adecuadas si no se cuenta con el apoyo de una apropiada educación pastoral y canónica.

En cierto modo, el siguiente testimonio de un Obispo diocesano ilustra esa apreciación:

"Desconocía yo antes de ser obispo el oficio de secretario y de notario del Obispado y la importancia de organizar bien los archivos diocesanos. Son puntos neurálgicos de la Curia cuya labor tal vez no se note, pero sí se ven los efectos negativos, si los secretarios, notarios $\mathrm{y}$ archiveros no funcionan bien"27.

Se podría extraer como una enseñanza específica de este recuerdo que se hace muy oportuno incorporar también el bagaje de conocimentos que colmen esa necesidad al preparar a las personas que colaboran con la autoridad en el gobierno del Pueblo de Dios y

\footnotetext{
${ }^{25}$ Ibid., n. 80.

${ }^{26}$ Ibid., n. 83.

${ }^{27}$ El párrafo citado corresponde al discurso conclusivo del entonces Obispo de Salamanca, España, Mons. Braulio Rodríguez Plaza en unas jornadas de estudio organizadas por la Asociación Española de Derecho Canónico cuyas actas fueron recogidas por F. R. AzNAR GIL, J. SAN José Prisco, (coords.), La curia diocesana. La función administrativa, Salamanca 2001, p. 388.
} 
servirse, para ello, de las lecciones teóricas y prácticas de Teología pastoral de los Sacramentos, Derecho de la función de santificar, Organización eclesiástica, Derecho parroquial y, también, Derecho de los procedimientos, intentando reflejar la manera de manifestarse las nociones en unos instrumentos de uso cotidiano como son los distintos formularios utilizados en las curias.

\section{Las posibilidades diferentes que ofrecen las colecciones de formularios}

Ciertamente la formalidad implica una conformación, es decir, adecuación de los contenidos a la forma que requiere de los titulares de la función administrativa fidelidad a las exigencias de procedimiento establecidas por la norma aplicable. Con esa conformación se busca el respeto de todas las posiciones jurídicas pertinentes y se facilita la participación de los fieles, concretándose de tal manera un aspecto de ese "saber mirar la grandeza sagrada del prójimo y descubrir a Dios en cada ser humano", en palabras del Papa Francisco citadas anteriormente. También de ese modo se refuerza la confianza en la autoridad por parte de los fieles, que comprueban que la participación de ellos mismos (en forma de consejos, peticiones, testimonios, pareceres, etc.) es determinante para la función administrativa y pueden advertir en mayor medida que la potestad se ejercita para el servicio.

Entender el porqué de la conformación favorece un mejor discernimiento de los procedimientos correctos que garantizan a quien lleva a cabo una tarea administrativa la posibilidad de disponer de los datos y de la ponderación suficiente para realizar una valoración acertada de los bienes en juego. En este sentido, se pide un cierto conocimiento previo del Derecho Canónico procedimental y el modo de aplicarse al propio contexto, para lo cual resulta de interés familiarizarse no sólo con los formularios en uso sino también con otros modelos que se utilizan en contextos distintos ${ }^{28}$. De esta manera,

\footnotetext{
${ }^{28}$ En esta línea, se manifestaba una de las sugerencias finales de los participantes en las jornadas mencionadas en la nota anterior y dirigidas a las curias diocesanas
} 
el servicio que se presta resulta más claro al facilitarse, a través de los formularios, el derecho de petición de los fieles ${ }^{29}$, la objetividad en los

españolas: "Habrá que ver la manera de ir mejorando o unificando programas que permitan un intercambio rápido y homologado de datos, incluso permitiría la homologación de impresos" (Ibid, p. 406). En cuanto a recopilaciones de formularios referidos a materias administrativas comunes, considero que conviene conocer la colección (en lengua italiana) www.quadernididirittoecclesiale.org, que, entre otras ventajas, se encuentra en la red y está actualizada; para formularios en lengua española, C. Heredia, Modelos de formularios, en L. Alessio, J. Bonet Alcón, A. Bunge, A. D. Busso, N. Dellaferrera, C. Heredia, V. Pinto (eds.), La Curia diocesana. Organización, diversos oficios, modelos de formularios, Curso organizado por la Facultad de Derecho Canónico y auspiciado por la Sociedad Argentina de Derecho Canónico, Buenos Aires, 27-29 de mayo 1996, Buenos Aires $1998^{2}$ (Colección Facultad de Derecho Canónico, 6), pp. 231-347 y J. SAN José Prisco, Derecho parroquial. Guía canónica y pastoral, Salamanca 2008, Anexos, pp. 465-530. En otras lenguas, R. R. Calvo, N. J. Klinger, Clergy procedural handbook, Washington DC, 1992; The Episcopal Commission on Canon The Episcopal Commission on Canon Law Catholic Bishop's Conference of Nigeria, The catholic formulary in accordante with the recise Code of Canon Law, Lagos 1997; J. Pelletier - Assemblée des ÉVÊQUES CATHOLIQUES DU QUÉBEC, SOCIÉTÉ CANADIENNE DE DROIT CANONIQUE Canonical and pastoral guide for parishes, Montréal 200633, A. INTERGUGLIELMI, I decreti singolari nell'esercizio della potestà amministrativa della Chiesa particolare. Studio giuridico-pratico sulla potestà amministrativa del Vescovo diocesano con schemi di decreto, Città del Vaticano 2012, pp. 385-454. Acerca del procedimiento se ha publicado recientemente el volumen de W. DAnIEL, The Art of Good Governance. A Guide to the Administrative Procedure for Just Decision-Making in the Catholic Church, Montréal 2015.

${ }^{29}$ Considero también útil conocer la legislación estatal sobre la materia, y como ejemplo me permito citar aquí los siguientes dos párrafos del art. 30 de la ley de Chile 19880 que establece bases de los procedimientos administrativos que rigen los actos de los organos de la Administracion del Estado, promulgada el 22 de mayo de 2003 y publicada siete días después:

"La Administración deberá establecer formularios de solicitudes, cuando se trate de procedimientos que impliquen la resolución numerosa de una serie de procedimientos. Los formularios mencionados estarán a disposición de los ciudadanos en las dependencias administrativas.

Los solicitantes podrán acompañar los documentos que estimen convenientes para precisar o completar los datos del formulario, los cuales deberán ser admitidos y tenidos en cuenta por el órgano al que se dirijan". 
procedimientos, la obtención de todos los datos necesarios (cf. cann. 50 y 63 CIC) así como también la síntesis y que quede constancia de la información recibida, evitándose errores de contenido, formulaciones confusas, posibles omisiones y olvidos. Gracias al buen uso de los formularios, los titulares de la función de gobierno eclesial y quienes con ellos colaboran, disponen de un apoyo valioso para realizar de modo justo, legítimo y oportuno el propio ministerio.

\section{The proper use of forms in the diocesan Curia as an expression of the good formality of the ecclesiastical administration}

Canonical documentary formalities are also needed to guide the People of God well. These formalities safeguard important values that contribute to the vitality of the Church in so far as they are fair, timely and adequately carried out. It is necessary to make known the collections of forms but, above all, to convey that the well-used formality is of great help to the substantial goods of the Church.

Palabras Claves: formulario; derecho administrativo canónico; formalidad adecuada

KEY wORDs: forms; administrative Canon Law; good formality

\section{Nota o Autorze:}

Prof. Javier Canosa - Professore Straordinario di Diritto amministrativo canonico della Facoltà di Diritto Canonico della Pontificia Università della Santa Croce a Roma. 